\title{
Environmental geochemistry and mineralogy of tantalum and niobium around a LCT pegmatite deposit of the Rudny Altai, East Kazakhstan
}

\section{LAURENT RICHARD, MARIYA SHINTASSOVA AND}

ASSEL ZHALGASBAYEVA

Nazarbayev University, School of Mining and Geosciences

Presenting Author: laurent.richard@nu.edu.kz

Tantalum and niobium are strategic metals increasingly used in various applications and technologies. If their behavior is well-known in magmatic petrology, surprisingly little is known about the low-temperature aqueous geochemistry and mineralogy of tantalum (Ta) and niobium $(\mathrm{Nb})$. It has been recently suggested that "aged" $\mathrm{Ta}_{2} \mathrm{O}_{5}$ may control the concentrations of Ta in surface waters [1]. However, besides the main ore minerals for $\mathrm{Ta}$ and $\mathrm{Nb}$ which belong to the tantalite-columbite series and the pyrochlore group of minerals and certainly control the behavior of $\mathrm{Ta}$ and $\mathrm{Nb}$ under hydrothermal conditions [2], examination of the last IMA list of approved minerals reveals an incredible diversity of $\mathrm{Ta}$ and $\mathrm{Nb}$ minerals. Considering the unusual geochemistry of rare-metal pegmatites, we postulate that other $\mathrm{Ta}$ - and $\mathrm{Nb}$-bearing mineral phases must form as a result of the low-temperature alteration of these pegmatites [3]. In order to verify this hypothesis, the stability domains of these minerals must be characterized by first estimating their Gibbs energies of formation, which can be made using an approach based on polyhedral methods together with reasonable geochemical assumptions. Following in the footsteps of Garrels [4] and extending the polyhedral method of Chermak \& Rimstidt [5] to include tantalum and niobium polyhedra, we estimate the Gibbs energies of formation of a number of $\mathrm{Ta}$ - and Nb-bearing silicates and oxides which may potentially form at low temperatures and may provide geochemically more realistic constraints on the concentrations of $\mathrm{Ta}$ and $\mathrm{Nb}$ in natural waters.

The work reported here is part of a larger project which aims at evaluating the environmental consequences of abandoned mining sites in the eastern region of Kazakhstan.

[1] Filella \& May (2019), Applied Geochemistry 109, 104402.

[2] Wood (2005), GAC Short Course Notes 17, 217-268.

[3] Singh \& Gilkes (1993), Clays \& Clay Minerals 41, 624630.

[4] Garrels (1957), American Mineralogist 42, 780-791.

[5] Chermak \& Rimstidt (1989), American Mineralogist 74, 1023-1031. 